\title{
Erratum to: The Effect of Enrolling in a Minority- Serving Institution for Black and Hispanic Students in Texas
}

\author{
Stella M. Flores • Toby J. Park
}

Published online: 29 August 2014

(C) Springer Science+Business Media New York 2014

\section{Erratum to: Res High Educ \\ DOI 10.1007/s11162-014-9342-y}

In the original publication of the article, some of the entries in Table 6 have not been displayed correctly. The corrected version of Table 6 is shown here.

The online version of the original article can be found under doi:10.1007/s11162-014-9342-y.

S. M. Flores $(\bowtie)$

Leadership, Policy, and Organizations, Vanderbilt University, 230 Appleton Place, GPC 414, Nashville, TN 37203, USA

e-mail: stella.m.flores@vanderbilt.edu

T. J. Park

Department of Educational Leadership and Policy Studies, Florida State University, 1205D Stone Building, Tallahassee, FL 32306-4452, USA 


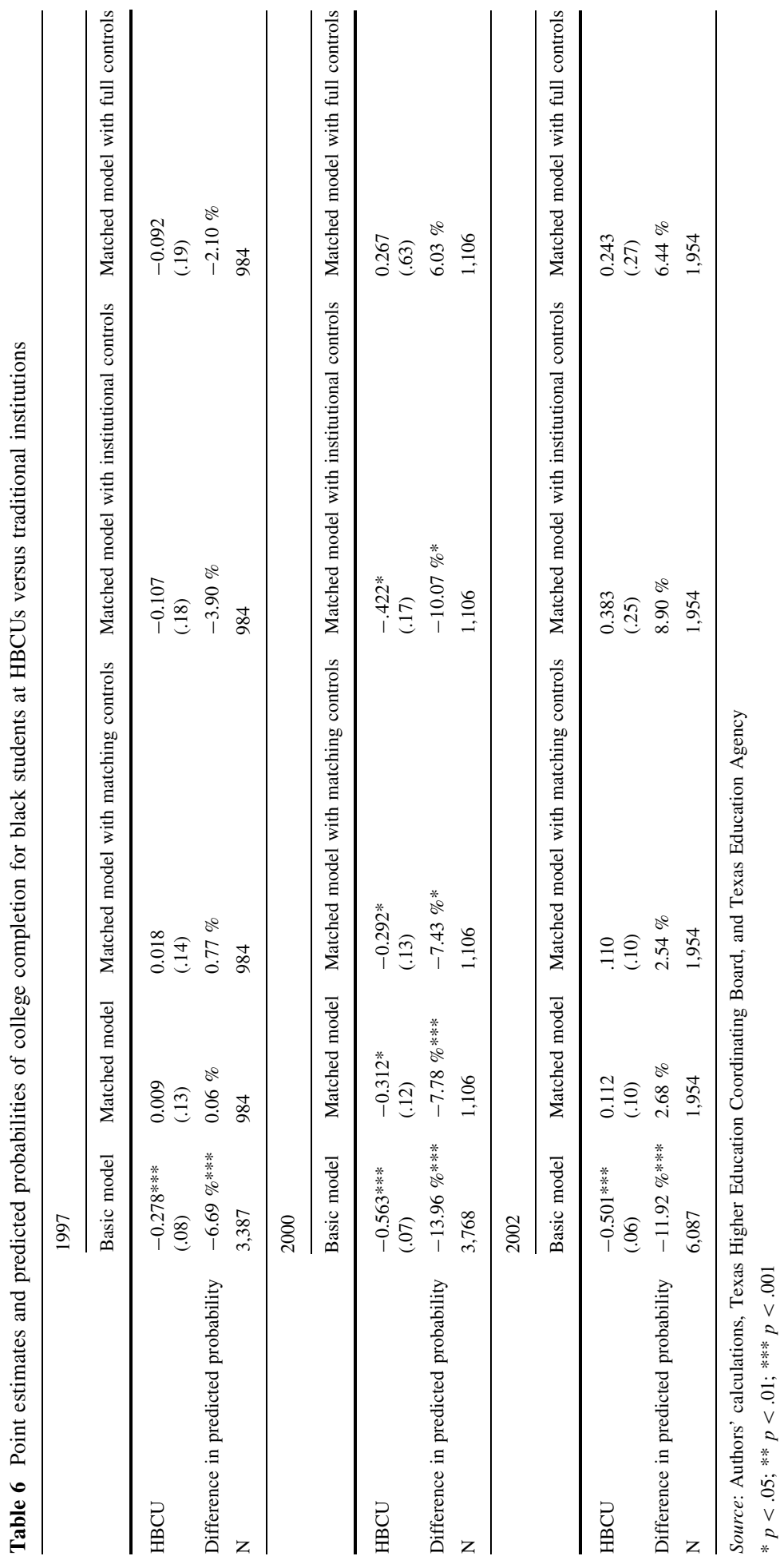

